\title{
Toxicidad pulmonar secundaria a bleomicina: reporte de caso y actualización clínica
}

\section{Pulmonary toxicity secondary to bleomycin: report of a case and clinical update}

Javier Leonardo Galindo Pedraza, MD. (1); Plutarco Garcia-Herreros Ochoa, MD., FCCP(2); Alfredo Saavedra Rodriguez, MD. (2); Edgar Alberto Sánchez Morales, MD, ${ }^{(3)}$

\section{RESUMEN}

Algunos antineoplásicos pueden producir toxicidad pulmonar de acuerdo con su perfil de acción; en tal sentido, la bleomicina es uno de los medicamentos en los que se ha reportado este evento. Este citostático puede lesionar el endotelio pulmonar y el epitelio alveolar para llevar a un proceso inflamatorio y fibrótico del intersticio con repercusiones potencialmente fatales.

La fisiopatología de la lesión pulmonar no se conoce del todo, de ahí que los virtuales blancos moleculares para la prevención y el tratamiento no se hayan definido.

En la actualidad el único tratamiento con una posible efectividad clínica es el uso temprano de corticoides para prevenir la falla respiratoria aguda y el desarrollo de fibrosis pulmonar.

Palabras clave: bleomicina, toxicidad pulmonar, fibrosis pulmonar.

\section{ABSTRACT}

Some antineoplastic agents can cause pulmonary toxicity, according to their action profile. Bleomycin is one of the drugs with which this event has been reported. This cytostatic can injure the pulmonary endothelium and the alveolar epithelium, which can lead to an inflammatory and fibrotic process of the interstice with potentially fatal repercussions.

The pathophysiology of the pulmonary injury is not fully understood, and therefore the potential molecular targets for prevention and treatment have not been defined. The only available treatment with possible clinical efficacy is early administration of corticoids, in order to prevent acute respiratory failure and pulmonary fibrosis.

Keywords: bleomycin, pulmonary toxicity, pulmonary fibrosis.

Rev Colomb Neumol 2013; 24 (2):97-101

\section{INTRODUCCIÓN}

Las bleomicinas son glicopéptidos con acción antibiótica aislados a partir del Streptomyces verticillos, Su actividad antineoplásica se centra en la inducción directa de la muerte celular y la inhibición de la angiogénesis (1), efectos que han permitido incluirla en es- quemas de manejo para linfomas, tumores de células germinales y sarcoma de Kaposi, entre otros (2).

La bleomicina sintetizada con uso clinico se compone de dos isoformas, la bleomicina A y la bleomicina $B$ (1). Su acción requiere de la unión transitoria a un metal reducido $\left(\mathrm{Fe}^{+2}\right)$ que al oxidarse $\left(\mathrm{Fe}^{+3}\right)$ forma la

\footnotetext{
(1) Medicina Interna, Universidad Nacional de Colombia.

(2) Neumologia. Profesor Unidad de apoyo en Neumologia, Universidad Nacional de Colombia.

(3) Neumologia. Coordinador Unidad de apoyo en Neumologia, Universidad Nacional de Colombia.
}

Correspondencia: Doctor Plutarco Garcia-Herreros Ochoa. Correo electrónico: plugarciherreros@gmail.com

Recibido: octubre 12 de 2012. Aceptado: noviembre 12 de 2012. 
bleomicina activa (bleomicina- $\mathrm{Fe}^{+3}-\mathrm{OOH}$ ), la cual tiene la capacidad de unirse a su blanco en el ADN donde produce el clivaje de la estructura (1).

Los mecanismos de toxicidad de la bleomicina están en relación con la acción directa del medicamento asi como la inducción de inflamación tisular. Los datos que subyacen a la fisiopatologia de la toxicidad no son del todo conocidos y los disponibles en la actualidad son extraídos de modelos animales.

\section{DESCRIPCIÓN DEL CASO}

Paciente de género masculino, de 21 años, con historia de un año de evolución de fiebre de origen desconocido y esplenomegalia, estudios inicialmente negativos incluyendo esplenectomía diagnóstica. Posteriormente, al desarrollar adenopatias retroperitoneales, se complementó el estudio con biopsia de las mismas que documentaron la existencia de linfoma Hodgkin variedad clásica con extensión a la médula ósea, para el cual se inició tratamiento con protocolo de quimioterapia ABVD.

Ingresó a urgencias, diez dias después del cuarto ciclo de quimioterapia, por fiebre cuantificada de $40^{\circ} \mathrm{C}$ asociada a rinorrea hialina, sin tos, disnea u otra sintomatología en relación. El hemograma de ingreso reportaba leucocitos de $2.250 / \mu \mathrm{L}$ con neutrófilos de $20 / \mu \mathrm{L}$ en su recuento absoluto, hemoglobina de $10,1 \mathrm{~g} / \mathrm{dL}$ y plaquetas de $509.000 / \mu \mathrm{L}$. La radiografía de tórax mostraba infiltrados reticulares difusos escasos (Figura 1).

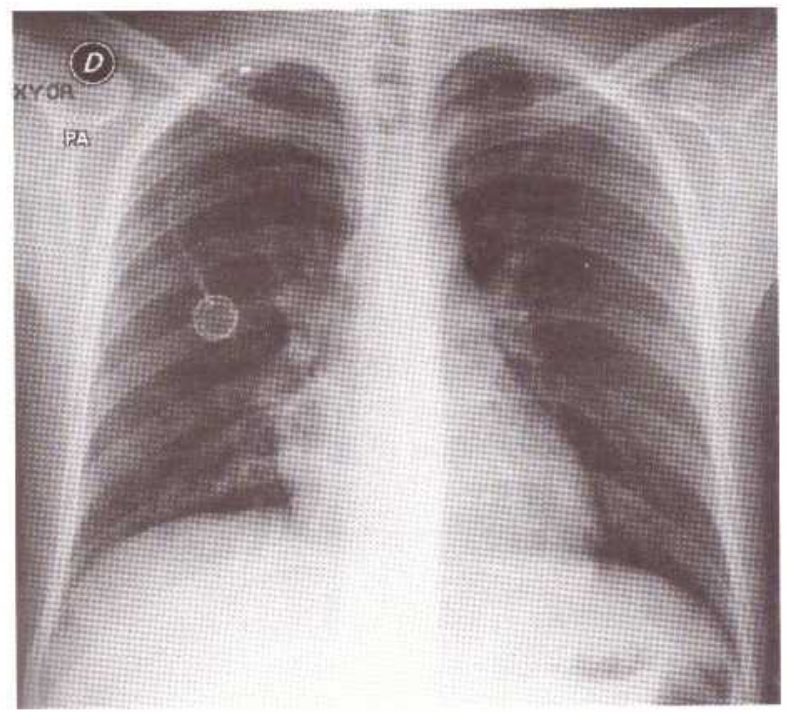

Figura 1. Radiografia de tórax al ingreso.
Considerando sus factores de riesgo, se inició manejo antibiótico dentro del protocolo de una neutropenia febril. Al segundo día de estancia presentó deterioro del patrón respiratorio con hipoxemia severa en la gasimetría arterial. Las imágenes de tórax mostraron progresión de los infiltrados intersticiales y alveolares respecto a la imagen del ingreso, con tendencia a la coalescencia, particularmente en el lóbulo medio. Con los resultados de una nueva radiografía y tomografía de tórax, se inició cubrimiento antibiótico empírico contra $P$. jirovecii con TMP/SMX y se adjuntó prednisolona $70 \mathrm{mg} / \mathrm{dia}$, según esquema Filadelfia (Figuras 2 y 3 ).

Se realizó una fibrobroncoscopia y en el lavado broncoalveolar se hallaron células epiteliales bronquiales con cambios reactivos, recuento celular normal (macrófagos $50 \%$, linfocitos $40 \%$, neutrófilos $10 \%$ ), coloraciones negativas (gram, ZN, PAS, Gomory y $\mathrm{KOH}$ ) y citología negativa para malignidad.

Se continuó el corticoide sistémico con la sospecha de toxicidad por bleomicina sin completar manejo contra P. jirovecii. Se observó remisión clínica e imaginológica y se dio de alta con corticoide sistémico oral (Figura 4).

\section{DISCUSIÓN}

Las reacciones secundarias al uso de bleomicina incluyen rash cutáneo, mucositis e hipersensibilidad. De todos los efectos adversos, la toxicidad pulmonar es el más grave, pues alcanza una incidencia de $2 \%$ a $46 \%$ y una mortalidad hasta de 3\% (3). Quienes sufren falla respiratoria aguda representan la mayor

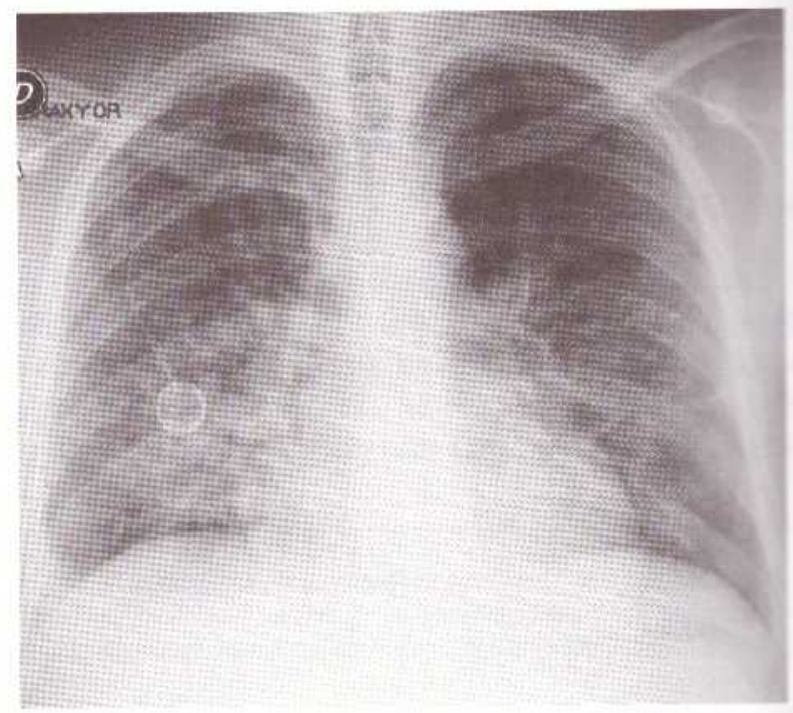

Figura 2. Radiografia de tórax control. 
bleomicina activa (bleomicina- $\mathrm{Fe}^{+3}-\mathrm{OOH}$ ), la cual tiene la capacidad de unirse a su blanco en el ADN donde produce el clivaje de la estructura (1).

Los mecanismos de toxicidad de la bleomicina están en relación con la acción directa del medicamento así como la inducción de inflamación tisular. Los datos que subyacen a la fisiopatologia de la toxicidad no son del todo conocidos y los disponibles en la actualidad son extraídos de modelos animales.

\section{DESCRIPCIÓN DEL CASO}

Paciente de género masculino, de 21 años, con historia de un año de evolución de fiebre de origen desconocido y esplenomegalia, estudios inicialmente negativos incluyendo esplenectomía diagnóstica. Posteriormente, al desarrollar adenopatias retroperitoneales, se complementó el estudio con biopsia de las mismas que documentaron la existencia de linfoma Hodgkin variedad clásica con extensión a la médula ósea, para el cual se inició tratamiento con protocolo de quimioterapia ABVD.

Ingresó a urgencias, diez días después del cuarto ciclo de quimioterapia, por fiebre cuantificada de $40^{\circ} \mathrm{C}$ asociada a rinorrea hialina, sin tos, disnea u otra sintomatología en relación. El hemograma de ingreso reportaba leucocitos de $2.250 / \mu \mathrm{L}$ con neutrófilos de $20 / \mu \mathrm{L}$ en su recuento absoluto, hemoglobina de $10,1 \mathrm{~g} / \mathrm{dL}$ y plaquetas de $509.000 / \mu \mathrm{L}$. La radiografía de tórax mostraba infiltrados reticulares difusos escasos (Figura 1).

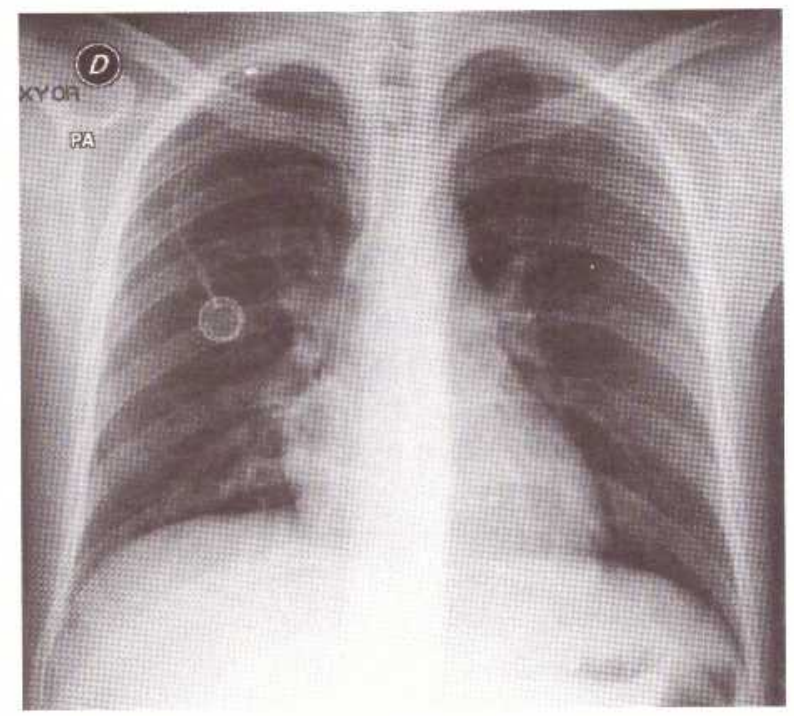

Figura 1. Radiografia de tórax al ingreso.
Considerando sus factores de riesgo, se inició manejo antibiótico dentro del protocolo de una neutropenia febril. Al segundo día de estancia presentó deterioro del patrón respiratorio con hipoxemia severa en la gasimetría arterial. Las imágenes de tórax mostraron progresión de los infiltrados intersticiales y alveolares respecto a la imagen del ingreso, con tendencia a la coalescencia, particularmente en el lóbulo medio. Con los resultados de una nueva radiografía y tomografia de tórax, se inició cubrimiento antibiótico empírico contra $P$. jirovecii con TMP/SMX y se adjuntó prednisolona $70 \mathrm{mg} / \mathrm{di} a$, según esquema Filadelfia (Figuras 2 y 3 ).

Se realizó una fibrobroncoscopia y en el lavado broncoalveolar se hallaron células epiteliales bronquiales con cambios reactivos, recuento celular normal (macrófagos $50 \%$, linfocitos $40 \%$, neutrófilos $10 \%$ ), coloraciones negativas (gram, ZN, PAS, Gomory y $\mathrm{KOH}$ ) y citología negativa para malignidad.

Se continuó el corticoide sistémico con la sospecha de toxicidad por bleomicina sin completar manejo contra $P$. jirovecii. Se observó remisión clínica e imaginológica y se dio de alta con corticoide sistémico oral (Figura 4).

\section{DISCUSIÓN}

Las reacciones secundarias al uso de bleomicina incluyen rash cutáneo, mucositis e hipersensibilidad. De todos los efectos adversos, la toxicidad pulmonar es el más grave, pues alcanza una incidencia de $2 \%$ a $46 \%$ y una mortalidad hasta de $3 \%$ (3). Quienes sufren falla respiratoria aguda representan la mayor

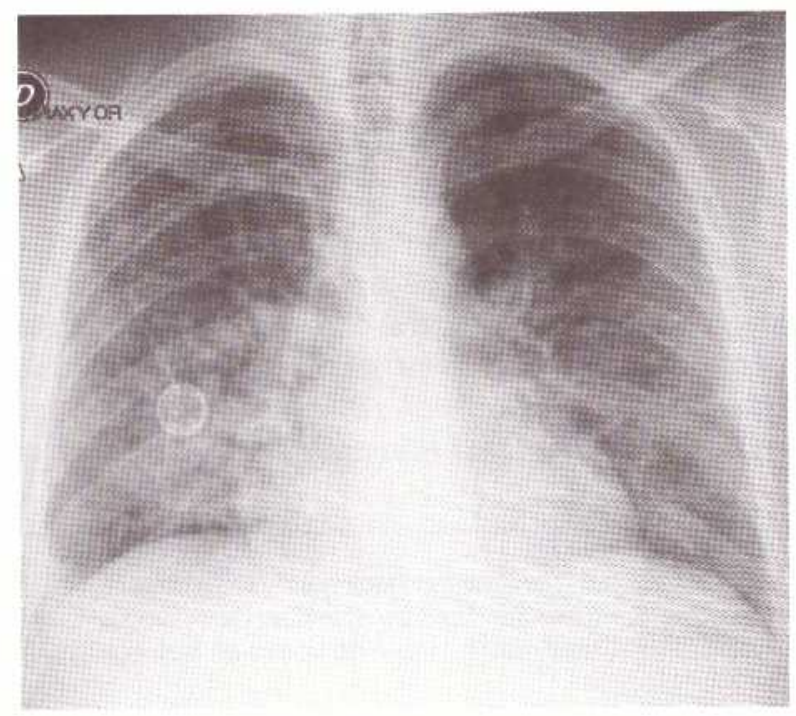

Figura 2. Radiografia de tórax control. 


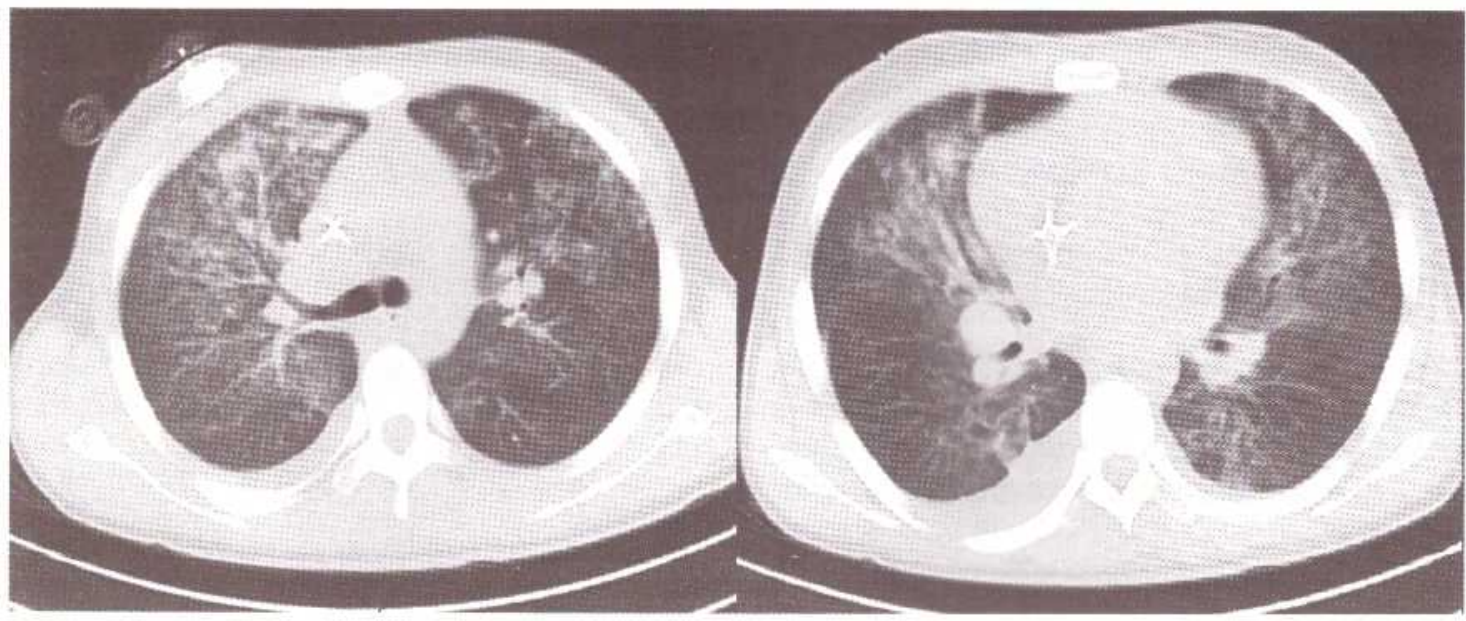

Figura 3. Cortes de tomografia de tórax contrastada control.

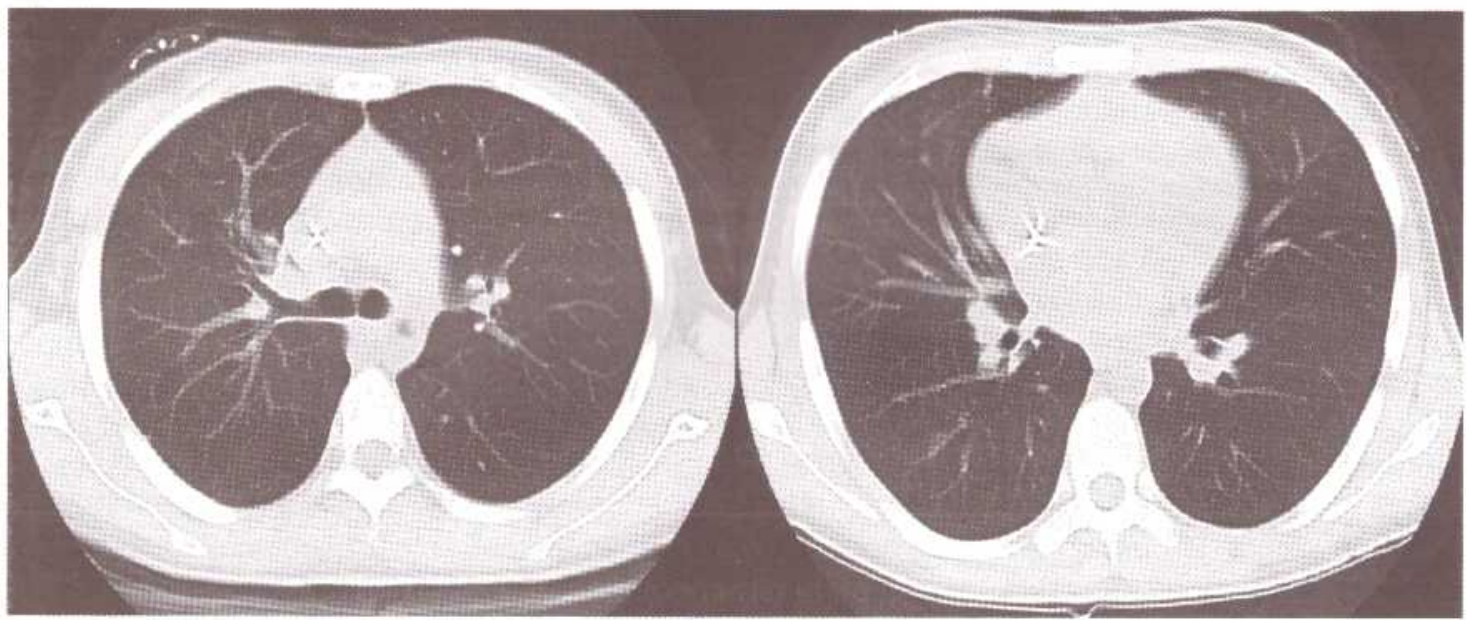

Figura 4. Cortes de tomografía de tórax contrastada posterior al inicio de corticoide.

mortalidad atribuible a la toxicidad, mientras aquellos que superan el episodio agudo no afectan su sobrevida a largo plazo (4).

La susceptibilidad del tejido pulmonar a la acción de la bleomicina se debe en parte a la carencia en este órgano de la hidrolasa inducida por bleomicina, enzima que permite el metabolismo del fármaco a nivel hepático, esplénico, intestinal y medular (2).

Uno de los mecanismos de lesión descritos corresponde a la reacción química de activación de la bleomicina por medio del $\mathrm{Fe}^{+2}$, que reduce el oxigeno y forma radicales libres que alteran la membrana alvéolo-capilar al oxidar lípidos, clivar ARN y ADN e hidrolizar proteinas (2). Asi mismo, al descomponerse la bleomicina genera radicales hidroxilo que forman especies reactivas lesivas (1).
La bleomicina también produce lesión endotelial directa y sintesis de citoquinas. El proceso tiene inicio al activarse el macrófago alveolar, el cual dirige la respuesta inflamatoria hacia Th1 por medio del factor de necrosis tumoral $\alpha$ y las interleucinas $1 \beta, 6$ y 18 que generan apoptosis del epitelio alveolar y del endotelio via Fas/Fas-ligando $(2,5)$.

Existe también un aumento en la expresión de moléculas de adhesión endotelial que favorece el paso de neutrófilos, macrófagos y linfocitos al intersticio (2). Paradójicamente, se ha encontrado que la expresión de E-selectinas, P-selectinas y V-CAM puede tener efecto protector posiblemente por linfocitos NK que podrían regular la inflamación (6).

Las citoquinas proinflamatorias inducen a la síntesis del factor de crecimiento transformante $\beta$, el 